\title{
Abordagens Multiobjetivo para o Problema de Sequenciamento de Aviões em Portões de Embarque e Desembarque
}

\author{
Gabriel Passos*, Priscila C. B. Rampazzo.
}

\begin{abstract}
Resumo
Com a crescente demanda por transporte aéreo, o controle de aeronaves e passageiros nos terminais dos aeroportos tem se tornado mais complexo a cada dia. Dentre as tarefas desempenhadas pelas equipes de administração dos aeroportos, destaca-se a de alocação de aeronaves em portões de embarque e desembarque(Gate Assignment). Esse problema possui grande importância pois sua solução envolve interesses de companhias aéreas, aeroportos e passageiros, assim, uma alocação indevida pode causar grandes prejuízos. O Gate Assignment é um problema da classe NP-difícil, logo, para problemas de grande porte, não existe método conhecido que encontre a solução ótima em tempo computacional viável, assim, nesses casos, buscam-se métodos alternativos. Propõe-se no presente trabalho um Algoritmo Genético(AG) Multiobjetivo, baseado no algoritmo NSGA-II [3], para solucionar instâncias de grande porte para o Gate Assignment. As soluções obtidas serão comparadas com o Método das Ponderações aplicado em um modelo de Programação Linear resolvido pelo solver CPLEX.
\end{abstract}

\section{Palavras-chave: \\ Otimização Multiobjetivo, Algoritmo Genético, Programação Linear.}

\section{Introdução}

No instante em que uma aeronave se aproxima do aeroporto, ela pode aterrissar imediatamente, ou deve aguardar, em voo, a liberação para o pouso, causando gasto excessivo de combustível. Caso a aeronave tenha que aguardar a liberação, associa-se a ela o tempo de espera do instante de chegada até o pouso. No momento da aterrisagem, a aeronave pode ser alocada em um portão ou pode ser destinada ao estacionamento, cuja capacidade é ilimitada. Os portões possuem acesso direto ao terminal de passageiros, entretanto, se uma aeronave é alocada no estacionamento, os passageiros devem ser transportados até o terminal por um ônibus, gerando gastos ao aeroporto e desconforto aos passageiros. As aeronaves necessitam de aproximadamente 30 minutos em solo. A alocação das aeronaves pode ser feita para minimizar: tempo de espera total, número de aeronaves no estacionamento, distância total percorrida, atraso total, etc. Dada necessidade de rápida resolução e a qualidade com que as soluções devem ser obtidas, propõe-se um Algoritmo Genético Multiobjetivo baseado no operador de seleção do NSGA-II para solucionar instâncias de grande porte como alternativa aos métodos exatos. Os objetivos considerados são a minimização da espera e do número de aeronaves no estacionamento.

\section{Resultados e Discussão}

O algoritmo proposto é formado pelas etapas básicas [1,2]: inicialização, crossover, mutação e seleção. Os indivíduos da população são codificados através de números reais. Na etapa de inicialização, a maior parcela da população é gerada aleatoriamente. Os demais indivíduos são gerados de forma a minimizar a espera ou o atraso. Para a etapa de crossover, são utilizados o crossover de um e de dois pontos. A mutação se consiste em alterar minimamente a codificação de um indivíduo de forma aleatória. Para a seleção, utilizou-se do operador presente no NSGA-II. Este operador aplica conceitos da otimização multiobjetivo para selecionar os indivíduos classificando-os em fronteiras segundo a relação de dominância das soluções. $\mathrm{Na}$ etapa de seleção, a fim de manter a diversidade, associa-se também a cada indivíduo uma medida da distância em relação aos indivíduos da mesma fronteira, assim, caso seja necessário selecionar entre dois ou mais indivíduos de uma mesma fronteira, o mais distante tem prioridade. Para os testes do algoritmo proposto, foram geradas duas instâncias. A primeira com 25 aeronaves e 5 portões de embarque, a segunda com 70 aeronaves e 15 portões de embarque. Os resultados do AG para cada instância foram comparados com o Método das Ponderações aplicado em um modelo de Programação Linear para o Gate Assignment solucionado pelo solver CPLEX. Devido à complexidade do problema, estipulouse um tempo limite de $3600 \mathrm{~s}$ para cada execução do solver. Para a primeira instância, o tempo de execução total do AG e do solver foram respectivamente 441,22 s e 10835,79 s. Para a segunda instância, os tempos foram de 1166,45 s para o AG e 32564,31 s para o solver. Destaca-se o fato de que em ambas as instâncias o conjunto de soluções não dominadas é o mesmo para ambos os métodos e que o AG obteve maior diversidade de soluções em um tempo computacional muito menor.

\section{Conclusões}

A característica exploratória do algoritmo genético proposto permitiu que uma fronteira Pareto-ótima com bons indivíduos fosse obtida de forma rápida, se destacando em relação ao Método das Ponderações, que além de demandar tempo, não obteve diversidade de indivíduos. Trabalhos futuros envolvem testes com mais instâncias e outros tipos de função objetivo para o problema.

\section{Agradecimentos}

O grupo agradece profundamente ao $\mathrm{PIBIC/CNPq}$ pelo financiamento ao projeto.

[1] Bäck, T., Fogel, D. B., e Michalewicz, Z. (2000a). Evolutionary Computation 1: Basic Algorithms and Operators. Institute of Physics Publishing, Bristol, UK, 1 edition.

[2] Bäck, T., Fogel, D. B., e Michalewicz, Z. (2000b). Evolutionary Computation 2: Advanced Algorithms and Operators. Institute of Physics Publishing, Bristol, UK, 1 edition.

[3] Deb, K., Pratap, A., Agarwal, S., e Meyarivan, T. (2002). A fast and elitist multiobjective genetic algorithm: Nsga-ii. IEEE transactions on evolutionary computation, 6(2):182-197. 